\title{
Is rational choice theory still a rational choice of theory?: A response to Opp
}

Gianluca Manzo

The self-archived postprint version of this journal article is available at Linköping University Institutional Repository (DiVA):

http:// urn.kb.se/ resolve?urn=urn:nbn:se:liu:diva-148771

N.B.: When citing this work, cite the original publication.

Manzo, G., (2013), Is rational choice theory still a rational choice of theory?: A response to Opp, Social Science Information, 52(3), 361-382. https:// doi.org/ 10.1177/ 0539018413488477

Original publication available at:

https:/ / doi.org/ 10.1177/0539018413488477

Copyright: SAGE Publications (UK and US)

http:// www.uk.sagepub.com/ home.nav 
Is rational choice theory still a rational choice of theory? A response to Opp

Gianluca Manzo

GEMASS-CNRS \& University of Paris-Sorbonne

\begin{abstract}
Authoritative rational choice theorists continue to argue that wide variants of rational choice theory should be regarded as the best starting-point to formulate theoretical hypotheses on the micro foundations of complex macro-level social dynamics. Building on recent writings on neo-classical rational choice theory, on behavioral economics and on cognitive psychology, the present article challenges this view and argues that: (1) neo-classical rational choice theory is an astonishingly malleable and powerful analytical device whose descriptive accuracy is nevertheless limited to a very specific class of choice settings; (2) the 'wide' sociological rational choice theory does not add anything original to the neo-classical framework on a conceptual level and it is also methodologically weaker; (3) at least four alternative action-oriented approaches that reject portrayal of actors as computational devices operating over probability distributions can be used to design sociological explanations that are descriptively accurate at the micro level.
\end{abstract}

\title{
Introduction
}

The publication in 1990 of the monumental The Foundations of Social Theory by James Coleman powerfully stimulated the resurgence of rational choice theorizing in sociology. Within the context of the lively debate about the strengths and the limitations of rational choice theory generated by this book, Peter Abell (1992) provocatively asked if rational choice theory could truly be regarded as a 'rational choice of theory'. His reply was that 'RAT appears to provide a point of departure. For these sorts of reasons, it should be accorded pride of place in our thinking ... Furthermore, there is little evidence of any serious competitor ... RAT is indeed a rational choice of theory - it is at the moment our least worst choice of framework (1992: 203).

Some twenty years on, the same argument continues to be endorsed by authoritative rational choice theorists like Karl-Dieter Opp, who has recently concluded his defense of the 'wide' version of rational choice theory as an empirically testable general theory of action with high explanatory power, claiming that it is highly problematic to renounce the application of RCT unless a better theory is available. This is not in sight. Dispensing with RCT would mean to give up a possibility to enhance our knowledge.'

This article is an attempt to challenge this statement. It asks the question: Do we still have strong reasons to consider a priori rational choice theories as the best starting-point to achieve empirically realistic and precise micro-founded explanations of macro-level social dynamics?

To anticipate the conclusion, my answer is that we do not. The basic argument is that the neo-classical rational choice theory developed and constantly reshaped 
in economics is an incredibly malleable and powerful analytical device whose descriptive accuracy is nevertheless limited to a very specific class of choice settings. Alternatively, contrary to what Opp claims, I suggest that the 'wide' version of rational choice theory is not really original compared to the fundamental conceptual core of neo-classical rational choice-theory and that it is also methodologically weaker. Thus, rational choice theory is currently trapped in the undesirable dilemma of being either formalized and strongly predictive but descriptively inaccurate, or more realistic (basically renouncing the assumption of preference consistency) but vague and weakly predictive. Given that currently there are theoretical alternatives that do not portray the actor as a more or less competent computational device operating over more or less biased probability distributions, which, I will maintain, constitutes the most fundamental feature of all variants of rational choice theory, how could one continue to claim that it is reasonable to regard rational choice theory as the best starting-point for seeking micro-founded sociological explanations?

I detail my argument as follows. The first section discusses the recent writings of Gintis, Binmore, and Gilboa on rational choice theory in economics, and suggests that the foundations of neo-classical rational choice theory are less restricted than economists and sociologists often claim. The second part reviews a selection of results within the field of behavioral economics and cognitive psychology and suggests that neo-classical rational choice theory is at the same time incredibly conceptually flexible and empirically descriptively inaccurate. The third section discusses the 'wide', sociological rational choice theory and argues that, compared to its neo-classical counterpart, sociological rational choice theory is at the same time conceptually unoriginal and methodologically weaker. The fourth section briefly presents four theoretical action-oriented approaches that, although to different extents, go beyond rational choice theory and suggests the triad heterogeneity/heuristics/networks as the focus to be developed further for better micro-level explanations of macro-level dynamics. A final short section sums up the main arguments.

\section{Rationality as preference consistency}

In order better to understand in what sense research in behavioral economics and in psychology has documented rationality failures that challenge the descriptive accuracy of rational choice theory (see section 2), it is important briefly to recall the version of rational choice theory that is the target of the criticism.

The rational choice theory at stake is that implied by the theory of revealed preferences, which, as acknowledged by Binmore (2011: 8), 'remains the orthodoxy in economic theory'. In modern terms, this kind of rational choice theory can be expressed by means of the so-called BPC model (Gintis, 2009a: Ch. 1 ), which portrays actors' choices as driven by actors' beliefs, preferences, and constraints. Among the three terms, actors' preferences represent the crucial element of the model because the properties that preferences are required to satisfy define the way actors' rationality is conceived. 
These properties are: (1) completeness (the actor is supposed always to be able to establish an order, not necessarily total, among alternatives); (2) transitivity (the actor is supposed to prefer $A$ to $C$ if $A$ is preferred to $B$ and $B$ is preferred to C); (3) independence of irrelevant alternatives (IIA) (if the actor prefers A to B, the actor is supposed to maintain this order when $C$ is added to the set of alternatives); (4) temporal stability (the actor is supposed to prefer A to B at $\mathrm{t}+$ $\mathrm{n}$ if he preferred A to B at $\mathrm{t}$ ) (Binmore, 2011: 9); (5) causal independence between feasibility and desirability (the actor is supposed not to change the order between $A$ and $B$ as a function of the accessibility of A/B) (Binmore, 2011: 6; Gilboa, 2010: 4).

If the actor's preferences meet these requirements, then the actor's preferences are said to be consistent. The rationality of the actor's choices amounts entirely to the consistency of his preferences. That is why Binmore (2011: 5) says that 'the words rationality and consistency are treated almost as synonyms in much modern work' and Gintis (2009a: 1) that 'the BPC model requires only preference consistency'.

Thus, the very conceptual bulk of orthodox rational choice theory in economics does not impose any constraints on the content of actors' preferences. One may be perfectly rational (in the sense defined above) when one is giving priority to others' welfare over one's own or when one behaves in such a way that one's own long-term welfare decreases (see Gintis, 2009a: 6-7).

The conceptual bulk of orthodox rational choice theory does not even require full information. When actors have to evaluate alternatives whose payoffs and/or consequences are uncertain, actors are assumed to formulate 'bayesian' or 'subjective priors', that is to say guesses as to the probability of these payoffs/consequences (see Gintis, 2009a: 11-16). Indeed, the content of actors' beliefs has essentially to do with these guesses (see Binmore, 2011).

Finally, when actors' rationality is understood in terms of preference consistency, the utility maximization principle becomes a mere logical consequence of preference consistency, not a substantive hypothesis aiming at describing actors' behavior. The mathematical proof of the fact that utility maximization simply follows from preference consistency (and vice-versa) is probably one of the most solid and deepest results of neo-classical economics (see Gilboa, 2010: appendix B).

Thus, Binmore's (2011), Gintis's (2009a), and Gilboa's (2010) analyses of the conceptual foundations of the theory of 'revealed preferences' suggest that the 'narrow neo- classical variant' of rational choice theory, to take Opp's own words (Opp, 2013, this issue: 340), is less 'narrow' than usually claimed (sometimes by economists themselves; see Binmore, 2011: 20). This is an important theoretical result that readers should keep in mind the better to appreciate the extent to which the 'wide' version of rational choice theory advocated by Opp is really wider than the orthodox, neo-classical rational choice theory (see section 3).

\section{Predictable irrationality}


An advantage of defining rational action in terms of preference consistency is that logic, probability theory and calculus can be mobilized to formulate clear expectations about what we should observe at micro and macro levels if actors behave in the way the theory portrays them. Over the last thirty years or so, these expectations have been systematically compared to real actors' behaviors, both in the lab and in the field (see DellaVigna, 2009), and the body of results accumulated strongly challenges the descriptive accuracy of the neo-classical version of rational choice theory.

Among the rationality failures documented, I am especially interested in those deviations that oblige us to ask whether it is realistic to continue to model actors' decisions in terms of more or less sophisticated operations that actors perform on more or less biased probability distributions. As attested by the long list of model modifications reviewed by DellaVigna (2009), this seems the crucial question because, as rationality failures were discovered, economists attempted to accommodate them within the standard model by introducing new/different parameters/functional forms rather than rejecting the core assumptions of the model. This is explicitly stated by Gilboa (2010: 9) when, within a discussion of the IIA assumption, he admits: 'rather than admitting that the definition of rationality involving separation of desirability from feasibility is very restricted, we come up with redefinitions of concepts to save the principle we were trying to promote'. This is what I suggest to call the 'turn-irrationality-into-rationality' strategy.

Preference stability is among the most frequently challenged assumptions on which economists apply this strategy. In the lab as well as in the field, actors tend to modify their priorities as a function of when the reward will be collected (for a deep literature review, see Shane et al., 2002). When actors are presented the same prospect between $\mathrm{X}$ and $\mathrm{Y}$ with $\mathrm{Y}>\mathrm{X}$ and $\mathrm{Y}$ to be obtained somehow later than $X$, a large majority of actors prefer $Y$ over $X$ if the reward is delivered in the distant future, whereas they prefer $\mathrm{X}$ to $\mathrm{Y}$ if the reward is delivered in the close present. As George Ainslie, one of the first scholars to document this phenomenon among animals and humans, writes: 'a number of experiments have shown preference for the smaller-earlier reward when the delay $\mathrm{T}-\mathrm{t}$ is short, and for the larger-later reward when this delay is long' (see Ainslie \& Haslam, 1992). Outside the lab, a large number of everyday, important choices in various decision settings, like savings, personal health or sex, exhibit preference reversal and show that actors systematically overestimate their capacity to sustain future costs (see DellaVigna, 2009: section 2.1).

The way economists react to these violations is clearly expressed by Gintis (2009a: 11): "In sum, time inconsistency doubtless exists and is important in modeling human behavior, but this does not imply that people are irrational in the weak sense of preference consistency. Indeed, we can model the behavior of time-inconsistent rational individuals by assuming they maximize their timedependent preference functions. "(O’Donoghue \& Rabin, 1999a,b, 2000, 2001) This time-dependency is usually modeled by introducing hyperbolic discounting in the standard utility function, that is a new parameter that modifies actors' subjective perceptions in such a way that temporally close rewards are far more 
positive than the perception of later rewards. While utility functions containing hyperbolic discounting have proven to be necessary to account for many macroscopic phenomena possibly related to preference reversal at the micro level, economists are aware that the mechanisms triggering time-inconsistency are still unclear (see Berns et al., 2007).

Violations of the central assumptions of preference stability are not limited to settings implying inter-temporal choices. The experiments that lead Kahneman and Tversky to formulate the prospect theory, and its generalization (see, respectively, Kahneman \& Tversky, 1979; Tversky \& Kahneman, 1992), concern choices among alternatives with known probabilities at a given point in time. The crucial point at stake here is an implicit but essential condition assuring preference stability, i.e. the principle of invariance according to which 'different representations of the same choice problem should yield the same preference' (Tversky \& Kahneman, 1986: 253). Indeed, if an actor prefers A to B and B' to A' when the net gain of the two prospects is the same, only their presentation being different, then the actor's behavior is inconsistent because the preferencestability assumption is violated. This is precisely what is recurrently observed when people face complex choices between medical treatments, insurance policies or risky prospects with (sometimes real) monetary outcomes. Moving from a positive (rates of success, survival probability or gain) to a negative (failures, death or losses) presentation as well as changes in the outcomes' scales tends to trigger preference reversal. In this literature, the impact of prospect presentation on prospect evaluation is called 'frame' effect (for a set of experiments showing this, see Tversky \& Kahneman, 1986: Table 1).

According to prospect theory, this violation of preference stability arises from three cognitive biases (the nature of which is still under debate; see section 4) that drive actors' perceptions: (1) actors' tendency to be more sensitive to losses than to gains (loss aversion); (2) actors' tendency to evaluate gains and losses not in absolute terms but by comparison with a reference point (status quo bias);4 (3) actors' tendency to over-weight small probabilities and to underweight moderate and high probabilities (certainty effect). Prospect theory integrates these three biases within the basic framework of the expected utility theory by means of appropriate functional forms (the so-called 'value' and 'weighting' functions) thus providing a more realistic account of the way actors compute the utility of a given outcome and the probability that each outcome will happen.

As for inter-temporal choices, the mathematics of prospect theory thus clearly shows that, despite the fact that the theory was proposed to account for a specific form of rationality failures, the theory remains within the basic framework of rational choice theory. Actors are still supposed to make computations over probability distributions. It is only the utility function that is modified, not the fundamental logic behind it. That is why Gintis (2009a: 25) states: 'The brilliant experiments by Kahneman, Tversky, and their coworkers clearly show that humans exhibit systematic biases in the way they make decisions. However, it should be clear that none of the above examples illustrates preference inconsistency once the appropriate parameter (current time, current 
position, status quo point) is admitted into preference function'. Tversky and Kahneman (1991: 1057) themselves confirm that prospect theory starts with rationality failures and comes back to neo-classical rationality. They reply indeed to the question 'is loss aversion irrational?' in the following way: 'The asymmetry of pain and pleasure is the ultimate justification of loss aversion in choice.

Because of this asymmetry a decision maker who seeks to maximize the experienced utility of outcomes is well advised to assign greater weight to negative than to positive consequences.'

Although more disputed (see, for instance, Birnbaum \& Bahra, 2012), violations of preference transitivity have also been documented (see, for instance, Loomes et al., 1991). Here again, formal models have been proposed to resorb intransitivity within the basic framework. In this case, while several solutions exist, the basic strategy consists in assuming that actors have complex distributions of mental states. In Regenwetter et al.'s (2011: 43) words, 'the decision maker has some probability distribution over mental states and chooses $\mathrm{x}$ over $\mathrm{y}$ if and only if her or his current mental state is one in which she or he prefers $x$ to $y^{\prime}$.

Adaptive and counter-adaptive preferences are well-known forms of interdependency between actors' desires and opportunities that violate the assumption of the causal independence between feasibility and desirability, another rationality requirement that looks descriptively inaccurate (see, for instance, Elster, 2007: Ch. 9). In this case, the 'turn- irrationality-into-rationality' strategy works by extending the actors' set of preferences in such a way that the 'carrier of utility' (Gilboa, 2010: 8) rather than the final outcomes matters (on the concept of 'process' and 'procedural' utility, see Frey et al., 2004). Everyday situations in which extending the set of actors' choice leads actors to modify their previously stated preference (as, for instance, when I decide to walk home instead of taking the subway as usual because I now have the chance to share the way home with a friend that I have unexpectedly met in the street) are also so frequent that even the assumption of independence of irrelevant alternatives is not easily defensible in terms of descriptive accuracy. By commenting on these kinds of violations, Gintis (2009a: 5) nicely expresses once more the usual way economists react to these violations: 'when IIA fails, it can be restored by suitably refining the choice set'.

Let me finally consider a phenomenon that suggests that actors sometimes simply ignore crucial elements that are necessary for associating utilities with alternatives thus making it impossible to rank them in such a way that preference consistency is fulfilled. Assessing the costs of a given option implies estimating not only its direct costs but also those of the alternatives potentially displaced by the alternative under consideration. Whilst the neo-classical rational choice model assumes that both types of costs are taken into account by decision-makers, experimental evidence suggests that 'opportunity costs are often neglected and that effort alone will not typically overcome this neglect' (Shane et al., 2009: 553). Thus, the problem with 'opportunity-cost neglect' is not that a given component of actors' utility function is incorrectly estimated but that one component is simple ignored. This is the case because opportunity costs 
usually are implicit, hence cognitively invisible. As shown by Spiller (2011), actors' capacity actively to generate invisible alternatives and their costs is variable across actors and is only activated under specific conditions. Again, economists' reaction to these results is to modify the basic framework to accommodate the contradiction between assumptions and reality. As acknowledged by DellaVigna (2009: 349), 'in general, models of limited attention can be rephrased as rational models with information costs in which less salient information has higher costs of acquisition'.

In sum, violations of the explicit and implicit (see note 4) core assumptions of the neo-classical rational choice theory are ubiquitous and well documented. As stressed by Shafir and LeBoeuf (2002: 500ff.), these violations are robust against variations in subjects' incentives, involvement, attention and expertise, and do not arise from subjects' misinterpretations of the problems/tasks to be solved. Furthermore, contrary to what is often argued, rationality failures are not limited to the laboratory. The long list of studies critically reviewed by DellaVigna (2009) concerns micro level and macroscopic regularities at odds with the neo-classical framework which are observed in real actors in real, largescale market settings.

I attempted to show that economists react to the observed contradictions between the theory's predictions and the choices of real actors on the basis of a conservative 'turn- irrationality-into-rationality' strategy. Instead of revising the very conceptual core of the framework, they constantly turn seeming irrationality into rationality. They do this by making actors' utility function more complex. New parameters and/or functional forms are introduced so that more complexity at the actor level is taken into account and preference consistency is re-established. There is no rhetoric in this, only good mathematics.

Contradictions are progressively ingurgitated and the basic framework is saved. Actors continue to be portrayed as performing operations on probability distributions under the constraints required by preference consistency.

This is a powerful strategy. As attested by the provocative oxymoron 'predictably irrational' (Ariely, 2010), economists have been able to capitalize on the systematic character of rationality failures to build formal models that account for and incorporate these failures. The recent debates around the 'new paternalism' (see Glaeser, 2006; Thaler \& Sunstein, 2003) arise from behavioral economics and build on formal models designed to develop strategies that rational policy-makers can use to cope with rationality failures of other, less sophisticated actors (for an overview, see DellaVigna, 2009: 360-365). From this perspective, Benartzi and Thaler's (2013) recent analysis of the retirementsavings crisis in the US is a good example of the power of the 'turn-irrationalityinto- rationality' strategy.

In spite of the predictive and cumulative power of this strategy, one may wonder if the fundamental 'as-if' logic underlying the strategy is acceptable from a descriptive point of view. The experimental and empirical evidence discussed so far suggests indeed that real actors facing complex decisions often prefer not to choose (DellaVigna, 2009: 355), to ignore fundamental components of the utility 
function that they are supposed to follow (Shane et al., 2009), and that they simply lack the capacity to formulate subjective probabilities and properly to update them (Gilboa, 2010: 56). Given these cognitive limitations, as stressed by Shafir and LeBoeuf (2002: 498), 'expectations of experienced utility are often inaccurate, whether they stem from biased retrospective evaluations or from misguided theories about the future'.

To portray actors as more or less competent computation-makers operating over more or less biased probability distributions seems more and more in contradiction with these observations. But what is the alternative? In the next section, I explain why the 'wide', sociological version of rational choice theory is not this alternative.

\section{Rationality as subjective rationality}

Given my insistence on the experimental and empirical evidence against the rational choice theory that constitutes the backbone of contemporary economics, readers familiar with debates on rational choice theory in sociology should expect that I am going to defend the argument that sociological rational choice theory constitutes the alternative to the neo-classical version of the theory (for an overview of rational choice theory in sociology, see, among others: Boudon, 1998a, 1998b, 2003; Cherkaoui, 2005: Ch. 3; Ermakoff, 2010, 2013; Goldthorpe, 1998; Hedström \& Stern, 2008; Kroneberg \& Kalter, 2012).

This is the position defended by Opp in the article under discussion (2013), as well as in Opp (1999). Opp (2013: 340-341) claims that the 'narrow neoclassical variant ... assumes, among other things, that individuals have full and correct information and that only egoistic motives matter'. There is instead a 'superior variant', i.e. 'the wide version of RCT that is increasingly accepted in the social sciences' (2013: 341). According to this variant, Opp argues, actors' preferences are not limited, in particular they are not required to be selforiented; actors' beliefs are not required to be correct; actors' perception of alternatives is purely subjective; actors are utility maximizers in a subjective sense; actors are not isolated (p. 341).

Given the frequency and the authority of the scholars that propose to distinguish between a narrow, economic and a (variety of) wide, sociological rational choice theory(ies) (see, for instance, Goldthorpe, 1998), it may seem improbable to question this distinction. However, Gilboa's, Gintis's and Binmore's convergent discussion of neo-classical rational choice theory that I referred to in the second section suggests that this distinction is based more on common (mis)representations of disciplinary boundaries than on a careful inspection of what the theory of 'revealed preference' really is. Indeed, while it is undeniable that many applications of this theory in micro and macro economics require extremely restrictive assumptions, Gilboa's, Gintis's and Binmore's re-reading of the foundational, formal works by Samuelson and Von Neumann and Morgenstern shows that the very conceptual core of neo-classical rational choice theory does not imply such a restriction. 
First, the conceptual core of neo-classical rational choice theory relies only and entirely on the assumption of preference consistency. The five properties defining preference consistency, hence actors' rationality, do not imply any restriction on the content of actors' preferences. Contrary to what Opp states, Gintis (2009a: 6) reminds us that, when rationality is defined in terms of preference consistency, 'rational does not imply self- interest. There is nothing irrational about caring for others, believing in fairness, or sacrificing for a social ideal. Nor do such preferences contradict decision theory.' Along the same lines, Binmore (2011: 21) notes: 'It isn't true that it is axiomatic in economic theory that people are selfish. ... to make this claim is to fall to understand the theory of revealed preference.'

The subtle but crucial point here is that, within the framework of neo-classical rational choice theory, actors' self-interest is not the cause but the consequence of actors' preferences. Whatever the content of these preferences is, if the actor acts consistently with these preferences, then he is maximizing his self-interest. Thus, what sociologists usually consider as the primum movens of economic rational choice theory is not in fact more than a logical consequence of the definition of rationality in terms of preference consistency. This is clearly expressed by the mathematics behind the connection between preference consistency and utility maximization (see Gilboa, 2010, appendix b: 'Formal models'; Gintis, 2009a: 4-6). The substantial emptiness of preference consistency is also proved by the ease with which economists are able to incorporate other-oriented preferences (Fehr \& Gintis, 2007) and concerns for fairness (see, for instance, Fehr \& Schmidt, 1999) in the basic conceptual framework without modifying any of its fundamental elements.

Second, Opp's claim that neo-classical rational choice theory postulates that actors must have correct beliefs is also in contrast with the definition of rational action in terms of preference consistency at the heart of neo-classical economics. As Gintis (2009a: 1) reminds us, 'preference consistency does not presuppose unlimited information-processing capacities and perfect knowledge'. Imperfect information, as well as any other source of belief distortion, simply implies that actors are not necessarily in a position properly to estimate the probabilities of certain happenings. The definition of rationality in terms of preference consistency, however, is silent about whether these probabilities should be objective or subjective. As testified by Bayesian decision theory (see Binmore, 2011: Ch. 7), subjective beliefs can be incorporated into the neo-classical framework without modifying any of its basic conceptual elements. Rationally bounded behaviors can always be framed in terms of preference consistency given the appropriate set of Bayesian priori (see Zambrano, 2005).

Finally, that neo-classical rational choice theory is based on an 'atomized actor', as claimed by Opp (and others), is also at odds with at least the following three facts: (1) as noted by Abell (1996), 'parametric' interactions, i.e. interdependencies among rational actors mediated by social aggregates like prices, constitute a foundational focus of neo- classical micro and macro economics; (2) 'strategic' interactions are extensively studied by game theory whose progressive evolution from simple to repeated, iterated and evolutionary 
games shows once again the astonishing flexibility of the neo-classical basic framework (see Gintis, 2009b); (3) as attested by research on identity economics (see, for instance, Akerlof \& Kranton, 2002) and on economic inequalities (see Durlauf, 2006), interaction- and network-based behaviors are important topics within contemporary economics. The point here is that none of these three strands of literature renounces the basic assumptions of the neo-classical rational actor models, thus showing that rationality as preference consistency and actors' social embeddedness are not only compatible in principle but also coupled in practice.

Thus, the distinction between a narrow and a wide variant of rational choice theory, where the former would dominate economics whereas the latter would free sociology from the limitations of the neo-classical framework, is less easily defensible than sociologists usually seem to think. It may be that Gintis's, Binmore's and Gilboa's interpretations of the theory of 'revealed' preference to which I have systematically referred in the previous pages is just one interpretation among others. However, the mathematics behind the definition of rationality as preference consistency as well as the way economists have progressively incorporated new elements into the original, orthodox framework suggest that the very conceptual core of this framework does not restrict actors' preferences to self-interest a priori, does not postulate objectivity over subjectivity and does not assume nor imply 'solipsism'. As a consequence, it is unjustified to claim, as Opp does, that the wide, sociological version(s) of rational choice theory is superior to the narrow, neo- classical framework. The definition of rational action as preference consistency already contains all the elements that Opp claims to be distinctive of the supposedly more realistic sociological variant of rational choice theory.

As anticipated, my argument is even more radical. To date I have only suggested that the 'wide' sociological variants of rational choice theory are conceptually unoriginal compared to the orthodox, neo-classical framework, when this is properly understood. Now I would add that the 'wide' sociological variants of rational choice theory have failed to develop a methodological framework of comparable analytical power.

The point at issue here is the principle of utility maximization. How do 'wide' rational choice theorists usually define this principle and how do they formally treat it? In this respect, Opp's description of what he considers the wide version of rational choice theory is symptomatic: maximization is neither formally defined nor mathematically supported.

As we saw earlier, the orthodox, neo-classical version of rational choice theory considers utility maximization as a logical consequence of the crucial assumption of the theory, i.e. preference consistency. As stated by Gintis (2009a: 6), 'if $\geq$ is a consistent preference relation, then there will always exist a preference function such that the individual behaves as if maximizing this preference function over the set A from which he or she is constrained to choose'. The beautiful mathematics behind the theory of revealed preferences proves that the reciprocal relation also holds, that is '... comparison between pairs is complete 
and transitive if and only if it can be described by maximization of a function (a utility function)' (Gilboa, 2010: 17).

In the article under discussion, Opp (2013: 340-341) claims that the wide version of rational choice theory is based upon utility maximization but he never speaks of rationality in terms of preference consistency. Should one interpret this omission as an implicit agreement with the biunivoc relation between utility maximization and preference consistency as defined by the neo-classical version of rational choice theory? If so, Opp's wide version of rational choice theory simply conflates into the narrow version that he wants to reject; if not, Opp should explain the meaning that utility maximization has when preference stability, completeness, transitivity, independence of irrelevant alternative, and causal independence between feasibility and desirability are not assumed.

From what Opp (2013: 341) writes about subjective rationality, his reply to this question should be that utility maximization should be understood in purely subjective terms: 'social action is determined by what the actors think is best for them'. This is insufficient to make a distinction between neo-classical and sociological rational choice theory. Gilboa (2010:17) makes this point clear when, to clarify the sense of utility maximization within the orthodox framework, he provocatively remarks: 'Mother Teresa could possibly be described as maximizing the number of healthy children in the world. That is, she maximized a certain function. Adolf Hitler tried to maximize the percentage of Aryan people in Germany. He also maximized a function. Thinking of Mother Teresa and Adolf Hitler as utility maximizers only says that each of them pursued a goal in a coherent way.' Thus, rationality as preference consistency also implies subjective utility maximization.

Not only does sociological rational choice theory à la Opp defines the concept of utility maximization less clearly than neo-classical rational choice theory, it also fails to provide a rigorous way to prove that a given behavior maximizes the actor's welfare. In neo-classical economics, this proof is produced by sophisticated mathematical tools, namely calculus: 'according to this revealed preference paradigm, utility is that function whose maximization is compatible with the choices of the decision maker' (Gilboa, 2010: 20). More technically, Binmore (2011: 14) makes explicit that 'finding an optimal $x$ then reduces to solving the maximization problem: $u(x)=\max u(a)$ with a.A'. The concept of optimality has a very precise definition based on the marginality principle. An optimal choice is a choice in which the increase in the actors' welfare when moving from A to B, or from A (B) to more A (B), is infinitesimally small. In this sense, Gilboa (2010: 30) states that the marginality principle is 'an extremely powerful tool in identifying solutions'. Usually, rational choice oriented sociologists defending wide, subjectively oriented versions of rational choice theory do not use calculus. Thus, how can they identify optimal solutions proving that the observed choice is the choice that maximizes the actors' subjectively perceived welfare?

I suspect that Opp's reply would be that this question should be answered on the basis of quantitative surveys or various in-depth qualitative data. According to 
Opp's empirical strategy indeed the relevance of cost-benefit considerations should be ascertained empirically by proving that a given indicator of subjectively perceived costs/benefits has an impact on the actor's behavior and that this effect is not spurious (see Opp, 1998; 1999: 176-179, 192-198). As the very balanced discussion in Kroneberg and Kalter (2012: 76-78) shows, this strategy has several problems. My main objections here are that (1) the existence of a statistically significant coefficient between one (more) cost/ benefit-related variable(s) and a given individual-level outcome does not prove that the underlying decision-making process is based on cost-benefit evaluations for the majority of the actors; and (2) that the existence of such correlations cannot be taken as a formal proof that the observed choice has a maximizing value.

In sum, Opp's distinction between a narrow, economic and a wide, sociological version of the rational choice theory is unconvincing. The elements that Opp regards as distinctive of the wide version in fact also characterize orthodox, neoclassical rational choice theory when this theory is properly understood. Furthermore, the wide version is conceptually weak with respect to the crucial element of utility maximization. In this connection, Opp does not provide a formal definition of what subjective utility maximization is; he does not explain how this principle can be defended without also assuming preference consistency; he does not clarify how the maximizing character of a given choice can be proved in a rigorous way. These problems are consequential for Opp's (2013: 352-353) plea for a program of 'empirical theory comparison'. Without a formal definition of the subjective utility maximization principle and without the indication of a rigorous tool to prove the maximizing character of actors' choices, the relative advantage of a 'wide' rational choice explanation over competing explanations cannot be formally demonstrated, thus making Opp's research proposal impossible to operationalize.

\section{Heterogeneity, heuristics and interactions}

A strong implication of the arguments that I defended in the three previous sections is that one should give priority to the neo-classical rational choice theory over the sociological rational choice theory if one believes that the choice settings under analysis can be realistically framed in terms of actors performing operations on probability distributions. Indeed, sociological rational choice theory does not considerably differ from the basic framework of the orthodox neo-classical version when the latter is properly understood, except with respect to the principle of utility maximization. Since this principle is less clearly defined on a conceptual level and not supported by a clear formal apparatus in sociology, there is no reason to prefer sociological rational choice theory à la Opp to neoclassical rational choice theory à la Gintis.

This statement does not amount in my intention to a claim that the neo-classical rational choice theory should be regarded as a general theory of action representing the necessary starting-point of any action-based explanation. I regard neo-classical rational choice theory and its continuous refinements as the best tool for a very specific and restricted class of choice settings, namely what Gintis (2009a: 237) calls 'routine choice', 'choice situations where ambiguities 
are absent, the choice set is clearly delineated, and payoffs are unmediated, so that no deliberation is involved beyond the comparison of feasible alternatives'. Following Binmore (2011: 23-24 and Ch. 9), one may add to this condition the following: the stronger actors' familiarity with probability and the actors' willingness to learn, the smaller the group under analysis, the higher the probability that the neo-classical rational choice theory can be descriptively accurate and fruitfully applied.

Often, however, these conditions are not met. What should we do in these cases? Since neo-classical rational choice theory is so powerful in accommodating deviations from rationality (as preference consistency), we may opt for a conservative attitude according to which the phenomenon under scrutiny is stretched in such a way that actors' behavior can be framed in terms of computation over probability distributions. This attitude is common among economists. For instance, Gintis (2009a: 246) claims that the '... dismissal of traditional decision theory may be emotionally satisfying, but it is immature, short-sighted, and scientifically destructive'. The essential (implicit) argument here is that there are no equally powerful alternatives to neo-classical rational choice theory, an argument overtly endorsed by Opp (2013: 352) with respect to the 'wide' sociological rational choice theory.

My orientation is different. If one does not take the risk radically to leave the neo- classical framework in order to attempt to build an alternative framework of comparable analytical power, one will never know if an alternative conceptual system is possible. Thus, to conclude, I briefly discuss four action-oriented approaches that overtly renounce conceiving actors as more or less competent computational devices operating over more or less biased probability distributions. The intersection of these four perspectives suggests that the quest for more realistic micro-level explanations of macro-level dynamics should systematically rely on three elements: (1) infra- and inter-actor heterogeneity in terms of action logic; (2) heuristic-driven behaviors; and (3) network embeddedness.

Although it is often associated with the rational choice tradition, Boudon's theory of ordinary rationality is the first conceptual framework that should be considered in order to build micro-level explanations when the neo-classical framework does not apply (see, for instance, Boudon, 1989, 1993, 1996, 2003). While there is an evident continuity between Opp's 'wide' conception of rational choice theory and Boudon's understanding of rational action, there are also two fundamental differences.

The first difference is that the principle of utility maximization completely disappears from the way social actors are portrayed by Boudon. Boudon's actors are radically different from computational devices operating over probability distributions. Within the framework of ordinary rationality, actors are seen as reason-makers, i.e. cognitive devices that spend time fabricating systems of reasons that explain in the actor's eyes what he does and what he believes. The cancellation of the principle of utility maximization is not a pure matter of vocabulary. This has strong implications for the kind of reasons that actors are 
allowed to manipulate. These reasons are no longer limited to the realm of instrumental, cost-benefit evaluations; as soon as the actor has a thought that he feels to be well grounded and publicly defensible, this thought can be mobilized to explain the actor's behavior. Utility maximization is not a problem anymore. There is no quantity to be maximized within the framework of ordinary rationality. The subjectively perceived coherence of the actor's system of reasons is the only relevant focus of the analysis.

The heterogeneity of reasons that the model of ordinary rationality allows is strictly associated with the second distinctive feature of this model compared to the neo-classical framework, namely the fact that the analytical distinction between the actor's preferences that are given and the actor's behavior that should be explained on the basis of these preferences is erased. The model of ordinary rationality has the ambition to study within an unitary framework the reasons that lead actors to endorse a certain set of preferences and the reasons that lead actors to select one specific option within this set (see, for instance, Boudon, 2011; Boudon \& Betton, 1999). This is a radical change from the neoclassical framework. As stated by Binmore (2011: 4), 'the orthodox position therefore confines rationality to the determination of means rather than ends'. Boudon's attempt to endogenize actors' preferences radically deviates from the neo-classical tradition.

Thus on a conceptual level, the theory of ordinary rationality constitutes an interesting alternative to neo-classical rational choice theory because it does not frame actors as computational devices operating over probability distributions and because it explicitly introduces within the action-oriented tradition the largest amount of infra-individual heterogeneity in terms of the types of reasons actors can mobilize. Empirically, the theory has generated useful explanatory insights at the micro level (see, for instance, Boudon's [1994] explanation of the same laboratory results that Kahneman and Tversky explained in terms of cognitive biases) as well as at the macro level (see, for instance, Boudon's [2004] explanation of several macroscopic trends in the values of Western societies).

To extend the theory of ordinary rationality some problems need to be resolved, however. First, as remarked by Abell (1992), the understanding of preferences and actions in terms of reasons implies that the distinction between rationality and irrationality is blurred. A priori, without any restriction on the kind of reasons actors can mobilize, prediction is difficult (see Manzo, 2012b). A posteriori the observer as well as the actor can always find good reasons to explain actors' values and beliefs, which makes the empirical test of the explanation problematic (see Goldthorpe, 1998). Second, while the theory admits a large amount of infra-individual heterogeneity, it tends to represent all actors as reason-makers. A given macroscopic outcome, however, is likely to be generated by a plurality of actors driven by different micro level dynamics. The theory does not say why the reason-maker dynamic predominates over the others.

To my understanding, the conceptual core of the desires/beliefs/opportunity (DBO) theory discussed by Hedström within the context of analytical sociology 
largely overlaps with Boudon's theory of ordinary rationality. Indeed, when one combines Hedström's (2005: 60-66) strong charge against the orthodox, neoclassical rational choice theory with his presentation of DBO theory, it is clear that DBO theory does not impose any constraint on actors' preferences, neither formal (completeness, transitivity, etc.) nor substantial (type of preferences admitted), and does not postulate subjective utility maximization. When Hedström (2005: 61; emphasis added) then claims that 'DBO theory makes no assumption that actors act rationally, however; it only assumes that they act reasonably and with intention', it becomes clear that rational action is equated to reason- based action within the DBO framework.

Thus, when Opp (2013: 341-343, 347) argues that the 'wide' version of rational choice theory he advocated and DBO theory are the same theory provided utility maximization and belief restrictions are introduced in the latter, Opp is simply asking for something that is overtly and intentionally excluded by the theory. Opp (1999: 176; emphasis added) himself wrote that 'rational choice theory is commonly identified by the assumption that preferences and constraints affect behavior and, most importantly, that individuals optimize in some way'. According to this definition, DBO theory is simply excluded from rational choice theory because DBO theory does not postulate any optimization principle (see Hedström, 2005: 61). DBO does not portray actors as computational devices that perform operations over probability distributions.

In this respect, Opp's (2013: 342) objection is that the absence of the principle of utility maximization makes the DBO theory indeterminate. As I argued in the previous section, the same indeterminacy characterizes the 'wide' version of rational choice theory that pretends to maintain the utility-maximization principle without imposing formal constraints on actors' preferences, which is what gives a rigorous meaning (and a powerful mathematical apparatus) to this principle within the neo-classical version of rational choice.

Thus, if DBO theory shares with the theory of ordinary rationality the two main elements that make these two theories exit from the rational choice paradigm, i.e. the absence of utility maximization and the fact that actors' reasons are not limited to cost- benefit considerations, DBO theory is open to two additional elements that remain somehow invisible within Boudon's theory of ordinary rationality. On the one hand, DBO theory does not postulate that the more or less conscious elaboration of a system of reasons is the only principle that always drives human behavior (see, for instance, Hedstrom 2005: 41,61), and, on the other hand, DBO theory frames actors' desires, beliefs and opportunity as the result of the complex chains of dyadic interactions in which actors are embedded (see Hedström, 2005: 42-59).

Concerning the latter element, Opp (2013: 354) thus seems excessively severe when he attacks analytical sociology for not having 'solved all the problems that critics of RCT mention time and again: explaining preferences and beliefs'. The DBO framework is certainly not in a position at the moment to claim that it has solved all problems with respect to preference and belief endogenization, but it has put on the sociological agenda a crucial element of the puzzle, i.e. the 
connection between social networks and actors' desires, beliefs, and opportunity.

A third action-oriented perspective that should be considered when the conditions to apply neo-classical rational choice theory are not met is the socalled 'dual-process' approach (for a detailed overview, see Evans, 2008). This is a wide array of theories developed within cognitive and social psychology on experimental bases to account for the fact that the reflexive, conscious, highly demanding mode of reasoning required by complex decision-making appears as largely variable across actors and, within the same actor, across situations. Dualprocess theories are heterogeneous, but the point common to all theories is the postulate that cognition works on the basis of two fundamentally different classes of processes, one being fast, automatic and unconscious, whereas the other is slow, effortful and conscious. These two classes of processes are often referred to as system 1 and system 2 . The most frequent conditions that increase the probability that actors' minds switch between the two systems are: (1) the extent to which a ready- to-use solution is available to be adopted; (2) the presence of unexpected information or events; (3) motivation (how costly a wrong decision will be); and (4) the amount of opportunity to think (the time and cognitive resources available) (see Chaiken \& Trope, 1999).

Kahneman's (2011) Thinking, Fast and Slow is an especially interesting example of the logic behind dual-system theories. As we saw earlier, prospect and the cumulative prospect theory were developed by Kahneman and Tversky to incorporate rationality failures within the basic framework of neo-classical rational choice theory. The main features of these theories are now overtly interpreted by Kahneman within the dual-process approach: 'Although Amos and I were not working with the two-systems model of the mind, it's clear now that there are three cognitive features at the heart of prospect theory ... They should be seen as operating characteristics of System 1' (Kahneman, 2011: 281283). The heuristics discovered by Kahneman and Tversky that actors use to edit prospects as well as more general heuristics like 'availability' and 'representativity', Kahneman argues, should also be seen as emanating from the automatic system 1 (2011: Pt II).

A slightly different understanding of the concept of heuristic is at the heart of the last action-oriented approach that I would like to consider here as a possible alternative to the neo-classical rational choice theory when the conditions of applicability of this theory are not satisfied. The so-called 'fast-and-frugal heuristic' research program builds on the explicit rejection of logic and probability theory as the benchmarks to be used to assess and to frame actors' rationality and decision-making (see Gigerenzer, 2008).

Gigerenzer and Gaissmaier (2011: 454) define heuristics in the following way: 'A heuristic is a strategy that ignores part of the information, with the goal of making decisions more quickly, frugally, and/or accurately than more complex methods.' As the definition clarifies and Gigerenzer explicitly states (Gigerenzer \& Gaissmaier, 2011: 545), heuristics are conceived in this research tradition as conscious strategies, not as intuitive short-cuts acting behind the back of actors 
as is the case in dual-process theories (on this point, see also Evans, 2008: 266). Compared to Kahneman, this conceptual difference leads to a difference in the methods used to study heuristics. Gigerenzer argues that heuristics must be formally modeled so that their consequences can be studied in a rigorous way and their adaptive value can be compared with more traditional and sophisticated decision-making procedures.

On the basis of a complex combination of observation, experimentation, and formal and computational models, Gigerenzer and co-workers have thus been able to accumulate a consistent amount of empirical and experimental evidence in favor of the adaptive power of a large collection of heuristics (see Gigenrenze et al., 2011; and, for a shorter but dense overview, Gigerenzer \& Gaissmaier, 2011). Among them, 'social heuristics', i.e. strategies relying on others' behavior to handle choice settings characterized by uncertainty, have received much attention and have been proven to be especially important to understand the link between social interactions and actors' preferences (for an overview, see Hertwig \& Herzog, 2009: 680-690).

For the debate around rational choice theory, one of the most notable results obtained by Gigerenzer and co-workers is that heuristics can reproduce the behaviors of actors facing complex decisions, like managers, consumers or physicians, better than more complex models of decision-making can do. This is the so-called 'less-is-more-effect'. This is an important result because it casts doubt on the conviction that neo-classical rational choice theory, despite its descriptive inaccuracy, should still be regarded as an appropriate normative theory, that is as a theory indicating the best decision-making process that actors should follow if they want to reach optimal solutions (Gigerenzer \& Brighton, 2009).

The 'less-is-more' effect has another important implication. A widespread conviction in economics and in sociology is that an action theory should reach a good balance between simplicity, realism and formal tractability. The difficulty is that the three terms seem to imply a trade-off so that the theory is trapped in the dilemma of being either simple, unrealistic but tractable or more complex and realistic but less tractable. This dilemma is well expressed by Tversky and Kahneman (1986: 273), for instance, when they remark that 'an adequate account of choice cannot ignore these effects of framing and context, even if they are normatively distasteful and mathematically intractable'.

The results accumulated within the 'fast-and-frugal heuristic' research program suggest that the equation between realism and complexity does necessarily hold. Indeed, heuristic-driven behaviors are at the same time simpler than (neoclassical) rational choice models and more realistic. If one accepts to move from calculus to (perhaps less elegant) algorithmic computation, then the problem of formal tractability is also solved. Agent-based modeling is indeed a powerful formalism to model 'rule-of-thumb' agents (see, for instance, Miller \& Page, 2004). Although still rare, some attempts to associate the 'fast-and-frugal heuristic' research program and computational agent-based modeling exist and they suggest that simple heuristics can be used as micro-level bases to reproduce 
complex macro-level patterns like the distribution of age at first marriage (see Todd et al., 2005) or the structure and the amount of status inequality (see Manzo \& Baldassarri, under evaluation).

In sum, while much work remains to be done, the theory of ordinary rationality, the DBO theory, the dual-process theories, and the 'fast-and-frugal heuristic' research program constitute interesting action-oriented theoretical perspectives that may fruitfully complement the variety of rational choice models available in economics and in sociology. While one may rightly consider that the four approaches are not equally distant from the rational choice paradigm, the theory of ordinary rationality and the 'fast-and-frugal heuristic' research program being at the two extremes of the continuum, the four approaches share a fundamental feature that makes them exit from rational choice theories: actors are not represented as more or less competent computational devices operating over more or less biased probability distributions. Thus, it seems descriptively inaccurate to consider that rational choice theory does not have competitors. These competitors exist, and there are good reasons, namely their higher descriptive accuracy at the micro level, to invest energy in developing them further.

\section{Conclusion}

In this article, I have taken Opp's most recent critical assessment of analytical sociology as an invitation to re-think the controversial issue of the value of rational choice theory for sociology. Compared to the numerous papers that have previously addressed this point in sociology, my analysis contains three distinctive features. First, I systematically exploited the writings of economists that defend orthodox, neo-classical rational choice theory but argue that this theory is often misunderstood by sociologists as well as by economists themselves. Second, I focused on the large experimental and empirical evidence that challenges the descriptive accuracy of orthodox, neo-classical rational choice theory. Third, I built on recent psychological approaches that study heuristic decision- making and systematically compare their performance to that of more complex, cognitively demanding forms of rational decision-making.

On this basis, I proposed four main arguments. First, I suggested that the neoclassical version of rational choice theory is an extremely powerful analytical device which relies on a strong and malleable conceptual core and on a rigorous formal apparatus. The way economists have been able progressively to incorporate rationality failures into the basic model is the best proof of this analytical power. Second, I argued that the claimed originality of the 'wide' sociological rational choice theory disappears as soon as the conceptual core of the orthodox, neo-classical framework is correctly understood and that, contrary to what their advocates constantly claim, the sociological rational choice theory loses the rigor of its economic counterpart. This is the case because the principle of utility maximization is often adopted in sociology without what justifies it in economics, i.e. the definition of rationality as preference consistency. As a consequence, the mathematics behind neo-classic rational choice theory is also lost, the 'wide' sociological version thus remaining without the formal device 
that is needed to prove that a given choice is an optimal solution. The third argument I defended is that, no matter how good economists are at reshaping the basic model in order to show that a posteriori any irrational behavior can in fact be modeled as if it were rational (i.e. in line with the formal properties defining preference consistency), it is now clear that, from a descriptive point of view, neo- classical rational choice theory is inaccurate and only has local applicability. Finally, I argued that it is counter-productive to react to this state of affairs by claiming that there is no theoretical alternative to the neo-classical rational choice framework and that, for this reason, we should continue to consider it as the best starting-point from which to build micro-level explanations. Theoretical approaches that do not portray the actor as a computational device operating over probability distributions exist, and they suggest an agenda for action-oriented sociologists focused on actors' heterogeneity, heuristic-driven behaviors and social interactions.

More than twenty years ago, Tversky and Kahneman (1986: 252) advanced the claim that: 'the logic of choice does not provide an adequate foundation for a descriptive theory of decision making. We argue that the deviations of actual behaviour from the normative model are too widespread to be ignored, too systematic to be dismissed as random errors, and too fundamental to be accommodated by relaxing the normative system.' They concluded their article by saying: 'perhaps the major finding of the present article is that axioms of rational choice are generally satisfied in transparent situations and often violated in nontransparent ones' (1986: 272).

The experimental and empirical evidence that has been accumulated over the last twenty years has regularly confirmed both statements. How then is it possible that so many sociologists continue to argue that rational choice theory should be regarded as a rational choice of theory, i.e. the best, general startingpoint for building micro-founded sociological explanations? This article did not intend to provide an answer to this puzzle. More modestly, it has attempted to bring into the debate new elements that make the puzzle even more difficult to solve.

\section{References}

Abbott A (2007) Mechanisms and relations. Sociologica 2. (doi: 10.2383/24754)

Abell P (1992) Is rational choice theory a rational choice of theory? In: Coleman JS, Fararo TJ (eds) Rational Choice Theory: Advocacy and critique. Newbury Park, CA: Sage, 183-207.

Abell P (1996) Sociological theory and rational choice theory. In: Turner BS (ed.) The Blackwell Companion to Social Theory. Oxford: Blackwell, 252-273.

Ainslie G, Haslam N (1992) Hyperbolic discounting. In: Loewenstein G, Elster J (eds) Choice Over Time. New York, NY: Russell Sage Foundation, 57-92. 
Akerlof GE, Kranton RE (2002) Identity and schooling: Some lessons for the economics of education. Journal of Economic Literature 40(4): 1167-1201.

Ariely D (2010) Predictably Irrational: The hidden forces that shape our decisions. New York, NY: Harper Perennial. Benartzi S, Thaler R H (2013) Behavioral economics and the retirement savings crisis. Science 339: 11521153.

Berns GS, Laibson D, Loewenstein G (2007) Intertemporal choice - toward an integrative framework. Trends in Cognitive Sciences 11(11): 482-488.

Binmore K (2011) Rational Decisions. Princeton, NJ: Princeton University Press. Birnbaum MH, Bahra JP (2012) Testing transitivity of preferences using linked designs. Judgment and Decision Making 7(5): 524-567.

Boudon R (1989) Subjective rationality and the explanation of social behavior. Rationality and Society 1(2): 171-196.

Boudon R (1993) Toward a synthetic theory of rationality. International Studies in the Philosophy of Science 7(1): 5-19.

Boudon R (1994) The Art of Self-Persuasion. Cambridge: Polity Press. Boudon R (1996) The cognitivist model: A generalized rational-choice model. Rationality and Society 8(2): 123-150.

Boudon R (1998a) Limitations of rational choice theory. American Journal of Sociology 104(3): 817-828.

Boudon R (1998b) Social mechanisms without black boxes. In: Hedström P, Swedberg R (eds) Social Mechanisms: An analytical approach to social theory. Cambridge: Cambridge University Press, 172-203.

Boudon R (2003) Beyond rational choice theory. Annual Review of Sociology 29: 1-21. Boudon R (2004) The Poverty of Relativism. Oxford: Bardwell Press.

Boudon R (2011) The cognitive approach to morality. In: Hitlin S, Vaisey S (eds) Handbook of the Sociology of Morality. New York, NY/Berlin: Springer, 15-33.

Boudon R, Betton E (1999) Explaining the feelings of justice. Ethical Theory and Moral Practice 2: 365-398. Chaiken S, Trope Y (1999) Dual-Process Theories in Social Psychology. New York, NY: The Guilford Press. Cherkaoui M (2005) Invisible Codes: Essays on generative mechanisms. Oxford: Bardwell Press.

DellaVigna S (2009) Psychology and economics: Evidence from the field. Journal of Economic Literature 47(2): 315-372.

Durlauf S (2006) Groups, social influences, and inequality: A memberships theory perspective on poverty traps. In: Bowles S, Durlauf S, Hoff K (eds) Poverty Traps. Princeton, NJ: Princeton University Press. 
Elster J (2007) Explaining Social Behaviour: More nuts and bolts for the social sciences. New York, NY: Cambridge University Press.

Ermakoff I (2010) Theory of practice, rational choice and historical change. Theory and Society 39: 527-553.

Ermakoff I (2013) Rational choice may take over. In: Gorski PS (ed.) Bourdieu and Historical Analysis. Durham, NC: Duke University Press: 89-108.

Evans J St BT (2008) Dual-processing accounts of reasoning, judgment, and social cognition. Annual Review of Psychology 59: 255-278.

Fehr E, Gintis H (2007) Human motivation and social cooperation: Experimental and analytical foundations. Annual Review of Sociology 33: 43-64.

Fehr E, Schmidt KM (1999) A theory of fairness, competition, and cooperation. The Quarterly Journal of Economics 114(3): 817-868.

Frey BS, Benz M, Stutzer A (2004) Introducing procedural utility: Not only what, but also how matters. Journal of Institutional and Theoretical Economics 160: $377-401$.

Gigerenzer G (2008) Rationality for Mortals: How people cope with uncertainty. Oxford: Oxford University Press.

Gigerenzer G, Brighton H (2009) Homo heuristicus: Why biased minds make better inferences. Topics in Cognitive Science 1: 107-143.

Gigerenzer G, Gaissmaier W (2011) Heuristic decision making. Annual Review of Psychology 62: 451-482.

Gigerenzer G, Hertwig R, Pachurt T (2011) Heuristics: The foundations of adaptive behavior. Oxford: Oxford University Press.

Gilboa I (2010) Rational Choice. Cambridge, MA: MIT Press

Gintis H (2009a) The Bounds of Reason: Game theory and the unification of the behavioral sciences . Princeton, NJ: Princeton University Press.

Gintis H (2009b) Game Theory Evolving: A problem-centered introduction to modeling strategic interaction. Princeton, NJ: Princeton University Press.

Glaeser EL (2006) Paternalism and psychology. The University of Chicago Law Review 73: 133- 156.

Goldthorpe J (1998) Rational action theory for sociology. The British Journal of Sociology 49(2): 167-192. 
Gross N (2009) A pragmatist theory of social mechanisms. American Sociological Review 74: 358-379.

Hedström P (2005) Dissecting the Social: On the principles of analytical sociology. Cambridge: Cambridge University Press.

Hedström P, Stern C (2008) Rational choice and sociology. In: Durlauf SN, Blume LE (eds) The New Palgrave Dictionary of Economics. New York, NY: Palgrave Macmillan, 872-877.

Hertwig R, Herzog SM (2009). Fast and frugal heuristics: Tools of social rationality. Social Cognition 27(5): 661-698.

Kahneman D (2011) Thinking, Fast and Slow. New York, NY: Farrar, Straus and Giroux.

Kahneman D, Tversky A (1979). Prospect theory: An analysis of decision under risk. Econometrica 47: 263-291.

Kroneberg C, Kalter F (2012) Rational choice theory and empirical research: Methodological and theoretical contributions in Europe. Annual Review of Sociology 38: 73-92.

Little D (2012) Analytical Sociology and the rest of sociology. Sociologica 1. (doi: $10.2383 / 36894)$

Lizardo $O$ (2012) Analytical Sociology's superfluous revolution: Comment on Little. Sociologica 1. (doi: 10.2383/36902)

Loomes G, Starmer C, Sugden R (1991) Observing violations of transitivity by experimental methods. Econometrica 59: 425-439.

Manzo G (2010) Analytical Sociology and its critics. European Journal of Sociology 51(1): 129- 170.

Manzo G (2012a) Full and sketched micro-foundations: The odd resurgence of a dubious distinction. Sociologica 1. (doi: 10.2383/36900)

Manzo G (2012b) Reason-based explanations and analytical sociology: A rejoinder to Boudon. European Journal of Social Sciences 50(2): 35-65.

Manzo G, Baldassarri D (under evaluation) Cumulative advantage, symmetry concern, and status inequality: An agent-based model of deference exchange in dyadic encounters.

Miller JH, Page SE (2004) The standing ovation problem. Complexity 9(5): 8-16.

Opp K-D (1998) Can and should rational choice theory be tested by survey research? The example of explaining collective political action. In: Blossfeld H-P, 
Prein G (eds) Rational Choice Theory and Large-Scale Data Analysis. Boulder, CO: Westview Press, 204-230.

Opp K-D (1999) Contending conceptions of the theory of rational action. Journal of Theoretical Politics 11(2): 171-202.

Opp K-D (2005) Explanations by mechanisms in the social sciences: Problems, advantages, and alternatives. Mind and Society 4(2): 163-178.

Opp K-D (2007) Review of: P. Hedström's Dissecting the Social. European Sociological Review 23: 115-122.

Opp K-D (2013) What is Analytical Sociology? Strengths and weaknesses of a new sociological research program. Social Science Information 52(3): 329-360.

Regenwetter M, Dana J, Davis-Stober C P (2011) Transitivity of preferences. Psychological Review 118(1): 42-56.

Shafir E, LeBoeuf R (2002) Rationality. Annual Review of Psychology 53: 491517.

Shane F, Loewenstein G, Donoghue TO (2002) Time discounting and time preference: A critical review. Journal of Economic Literature 40: 351-401.

Shane F, Novemsky N, Wang J, Dhar R, et al. (2009) Opportunity cost neglect. Journal of Consumer Research 36: 553-561.

Spiller SA (2011) Opportunity cost consideration. Journal of Consumer Research 38(4): 595-610.

Thaler RH, Sunstein CR (2003) Libertarian paternalism. The American Economic Review 93(2): 175-179.

Todd PM, Billari FC, Simão J (2005) Aggregate age-at-marriage patterns from individual mate- search heuristics. Demography 42(3): 559-574.

Tversky A, Kahneman D (1986) Rational choice and the framing of decisions. Journal of Business 59: 251-278.

Tversky A, Kahneman D (1991) Loss aversion in riskless choice: A referencedependent model. Quarterly Journal of Economics 106: 1039-1061.

Tversky A, Kahneman D (1992) Advances in prospect theory: Cumulative representation of uncertainty. Journal of Risk and Uncertainty 5: 297-323.

Zambrano E (2005) Testable implications of subjective expected utility theory. Games and Economic Behavior 53: 262-268. 